\title{
An Emerging Role for IQGAP1 in Regulating Protein Traffic
}

\author{
Mahasin A. Osman \\ Department of Molecular Pharmacology, Physiology and Biotechnology, Division of \\ Biology and Medicine, Alpert School of Medicine, Brown University, Providence, RI \\ E-mail: Mahasin Osman@Brown.edu \\ Received February 4, 2010; Revised April 14, 2010; Accepted April 15, 2010; Published May 18, 2010
}

IQGAP1, an effector of CDC42p GTPase, is a widely conserved, multifunctional protein that bundles $\mathrm{F}$-actin through its $\mathrm{N}$-terminus and binds microtubules through its $\mathrm{C}$ terminus to modulate the cell architecture. It has emerged as a potential oncogene associated with diverse human cancers. Therefore, IQGAP1 has been heavily investigated; regardless, its precise cellular function remains unclear. Work from yeast suggests that IQGAP1 plays an important role in directed cell growth, which is a conserved feature crucial to morphogenesis, division axis, and body plan determination. New evidence suggests a conserved role for IQGAP1 in protein synthesis and membrane traffic, which may help to explain the diversity of its cellular functions. Membrane traffic mediates infections by intracellular pathogens and a range of degenerative human diseases arise from dysfunctions in intracellular traffic; thus, elucidating the mechanisms of cellular traffic will be important in order to understand the basis of a wide range of inherited and acquired human diseases. Recent evidence suggests that IQGAP1 plays its role in cell growth through regulating the conserved mTOR pathway. The mTOR signaling cascade has been implicated in membrane traffic and is activated in nearly all human cancers, but clinical response to the mTOR-specific inhibitor rapamycin has been disappointing. Thus, understanding the regulators of this pathway will be crucial in order to identify predictors of rapamycin sensitivity. In this review, I discuss emerging evidence that supports a potential role of IQGAP1 in regulating membrane traffic via regulating the $\mathrm{mTOR}$ pathway.

KEYWORDS: IQGAP1, lqg1p, mTOR, Cdc42, exocyst, protein trafficking, cell proliferation

\section{MEMBRANE TRAFFIC IS FUNDAMENTAL TO CELLULAR FUNCTIONING}

Membrane traffic underlies fundamental cellular functions such as cell growth, division, and cell polarity required for migration, maintenance of tissue organization, and morphogenesis. Newly synthesized proteins are cotranslationally inserted into the endoplasmic reticulum (ER) membrane, properly folded and exported into the Golgi, and sorted in the trans-Golgi networks (TGN) for delivery to endosomes, lysosome secretory granules, and plasma membranes[1,2]. Membrane traffic is mediated by vesicular transport with the actin and the microtubule cytoskeleton serving as tracks, and their associated motor proteins as propellers $[3,4,5,6]$. 
Sequencing of the human genome revealed that a range of inherited human diseases arises from dysfunctions in protein traffic[7,8]. Membrane traffic also mediates acquired human diseases caused by infectious agents[9] and it has been implicated recently in the etiology of human cancer[10,11]. Therefore, elucidating the molecular basis of membrane traffic will be crucial for understanding the mechanisms of morphogenesis, and for treatment of degenerative and acquired human diseases ranging from cancer, cystic fibrosis, and Alzheimer's to AIDS and autoimmune disorders. Many of the studies on vesicular traffic have focused on the role of the key regulators, the Rab and the tethering proteins $[9,12,13]$, which represents only the tip of the iceberg in the molecular machineries regulating this multistep and complex cellular process.

\section{MEMBRANE TRAFFIC AND THE ROLE OF THE ACTIN CYTOSKELETON DYNAMICS}

Two types of small GTPases are involved in the regulation of this process. Vesicular movement is regulated by the Rab GTPases[9,14], and the actin cytoskeleton is regulated by the Rho GTPases that regulate membrane protrusions and vesicular traffic mainly by stimulating actin filaments (F-actin) polymerization[3]. In this respect, $\mathrm{CDC} 42$ has been shown to regulate retrograde ER $>$ Golgi transport in an N-WASP-dependent manner[15]. Accumulated evidence now enforces the idea that CDC42 regulates post-Golgi traffic in an F-actin-dependent manner[16,17]. Therefore, the actin cytoskeleton dynamics play crucial roles throughout the route from the ER to the plasma membrane, where the tethering proteins, such as the exocyst, play an important role that also requires F-actin polymerization[18].

However, it has long been observed that the vesicles arriving from the inner cytosol have to overcome the physical barrier imposed by the dense actin meshwork underneath the plasma membrane in order to dock on the plasma membrane and prime into the readily releasable state[19]. Recent advancements in microscopy further revealed that dynamic actin remodeling is crucial for exocytosis in two important steps. During docking and tethering of the exocytic vesicle, actin polymerization is required[6]. During a more distal step involving fusion and release, actin meshwork disassembly is required[20,21,22]. The molecular basis of these remodeling events is poorly understood. However, the kinase PKC $\varepsilon$ has been shown recently to play a critical role in F-actin disassembly following the docking and tethering step of transport vesicles[20,23,24].

Therefore, $\mathrm{CDC} 42$ and $\mathrm{PKC} \varepsilon$ are both required for actin remodeling during vesicular traffic. The molecular mechanism(s) underlying their role is still unknown. Evidence from yeast and mammalian cells suggests IQGAP1 as an important player in this process. It plays an essential and conserved role in bundling F-actin[25,26,27], is both an upstream activator and a downstream effector of CDC42, and it regulates protein synthesis and exocytosis[28,29]. Moreover, IQGAP1 appears to be a substrate for $\mathrm{PKC} \varepsilon[30]$.

\section{IQGAP1 AS A MASTER REGULATOR OF ACTIN DYNAMICS}

Mammalian IQGAP1 (Fig. 1A) is a conserved, multidomain, and multifunctional member of a threeisoform family of proteins that differs in tissue distribution and function, and has been the subject of many reviews. It was identified as a target for the Rho GTPases CDC42 and Rac1, but displays no GAP activity towards them $[31,32,33,34]$, in part due to substitution of the catalytic "arginine finger" with a conserved threonine at position 1046 of its RasGAP domain GRD[35]. Further, it interacts with a diverse number of cellular proteins, such as the myosin-essential light chain[36], and integrates signaling networks[37,38]. In many cell types, IQGAP1 localizes to Golgi, the ER, and to the plasma membranes[26,29,33,39]. Despite the evidence that it plays a role as a cortical receptor for microtubule plus ends via CLIP170[39], the current paradigm is that IQGAP1 is the principal regulator of dynamic F-actin assembly at localized cellular sites[40,41]. IQGAP1 promotes actin nucleation and cross-links actin filaments with the Arp2/3 complex 
A

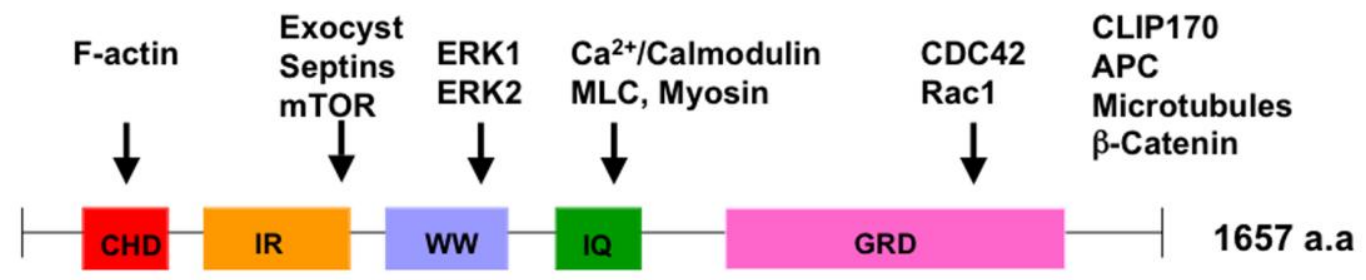

Protein-Protein interaction

CDC42 Binding and activation
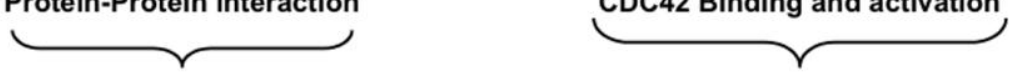

B

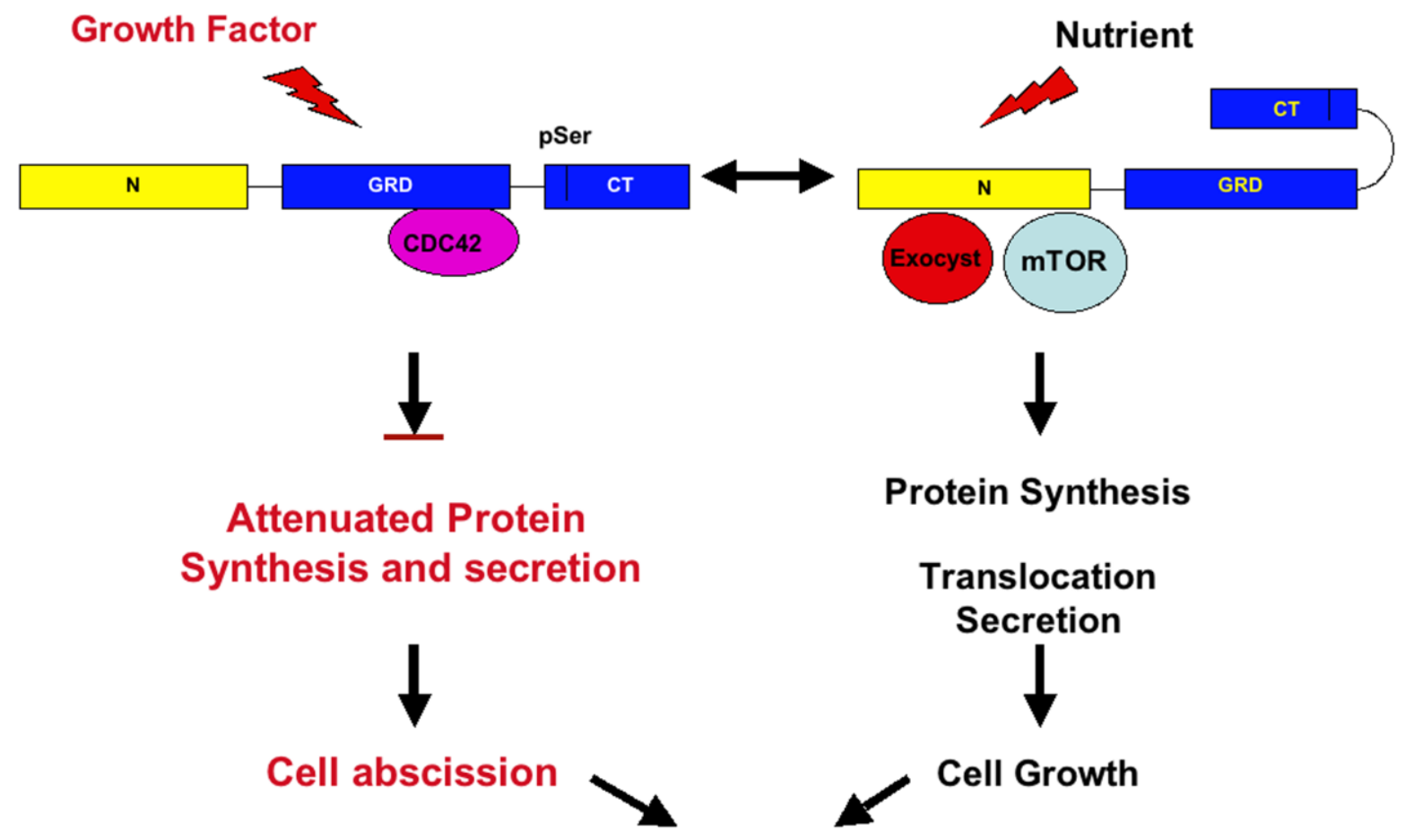

\section{Regulated Cell Proliferation}

FIGURE 1. IQGAP1 is a modular, multifunctional, signaling protein. (A) Schematic representation of IQGAP1 domain structure and a list of some of its binding partners. CHD: Calponin Homology Domain; IR: specific IQGAP Repeats; WW: proline-rich domain resembling the SH3 interacting domains; IQ: 8 IQ motifs that bind $\mathrm{Ca}^{2+}$ calmodulin and myosin; GRD: rasGAP-Related Domain containing sequences that bind CDC42 and Rac1. (B) A hypothetical model representing the regulatory role of IQGAP1 in protein synthesis and trafficking by which it couples cell growth and division to regulate cell proliferation. IQGAP1 is a conformational switch regulated by phosphorylation and protein-protein interaction (see text for detail). In response to nutrients, IQGAP1 operates in a closed form generated by folding of the C-terminus[29] and interaction with mTOR to promote protein synthesis, and the exocyst to promote secretion, which ultimately results in cell growth. In response to mitogenic signals, IQGAP1 is phosphorylated, leading to binding and activation of CDC42, which in turn results in attenuated secretion and cell growth and promotion of cell division[44].

and N-WASP[26,27]. Significantly, Bloom and colleagues[42] demonstrated that a single monomeric calponin homology domain (CHD) of IQGAP1 could bind F-actin with high affinity. Furthermore, 
IQGAP1 interacts specifically with the diaphanous formin mDia1, recruiting it to local sites of F-actin assembly, such as the leading front of migrating cells or the phagocytic cup[41,43]. The range of biological consequences of the IQGAP1 role in F-actin polymerization is yet to be fully appreciated, but it is likely to be key to its role in regulating protein traffic at different sites in the cell.

Upstream regulators of IQGAP1's function in F-actin bundling are yet to be identified, but PKCE is likely to be one. Biochemical evidence demonstrated that PKC $\varepsilon$ phosphorylates IQGAP1 at the Cterminal serine1443, enhancing its binding to CDC42-GTP during cell scattering[30]. Recent evidence suggested that Ser1443 phosphorylation and binding to CDC42, which attenuates exocytosis[29], are required for IQGAP1 to promote cell migration and transformed phenotypes[44]. Together, these findings suggest that PKCe likely regulates IQGAP1 function in bundling F-actin, as well as in regulating exocytosis, and that these two activities are interconnected. Below, I review the evidence supporting a role for IQGAP1 in regulating membrane traffic.

\section{IQGAP1 AS A REGULATOR OF PROTEIN TRAFFIC}

A role for IQGAP1 in protein traffic was first suggested by work in the budding yeast Saccharomyces cerevisiae and followed in different mammalian cell types. In the following two sections, I discuss evidence from yeast and mammals, respectively.

\section{Yeast IQGAP1, lqg1p, and Protein Traffic}

The budding yeast $S$. cerevisiae buds once per cell cycle using cortical positional cues to mark the division site by initiating a bud early in G1, thereby committing to its division axis[45,46]. Haploid yeast divides in such a manner that a bud is formed next to the previous division site, thus resulting in an axial budding pattern[45]. Genetic analyses have identified Ax11p, Ax2p, Bud3p, Bud4p, and the septins as axial markers for bud site selection[45,47,48]. Null or conditional lethal mutations in each of these genes result in a bipolar budding pattern in the haploid yeast without an effect on the diploid cells $[45,47,48]$. The positional signal imposed by the bud site selection proteins is decoded and transmitted by the polarity establishment GTPases Bud1p and Cdc42p, which polarize the actin cytoskeleton[49,50,51] and the secretory pathway $[52,53]$ to that site. Fusion of the secretory vesicles at the target site requires a protein complex, the exocyst[51,54,55,56,57], some of its members, such as Sec3p and Sec $4 p$, to localize to the bud tip to promote growth[58,59], then reorient to the mother-bud neck to promote cytokinesis[53]. Sec3p serves as a landmark for localizing the exocyst[54,60]and its polarized localization has been suggested to require the small GTPases Rho1[54] and Cdc42p[61]. Additionally, a recent study demonstrated that the Exo70p subunit of the exocyst serves as a target for both Cdc42 and Rho3 function in polarized exocytosis[62]. A molecular link between the exocyst and the positional markers, and how the exocyst docks to the site of the future bud to promote growth, remain important questions. Similarly, the Cdc42p effector(s) mediating its function in general budding and the mechanism by which it is achieved remain poorly understood.

However, Iqg1p, the ortholog of mammalian IQGAP1, has emerged as an important player in linking targeted exocytosis to directed cell growth and division, i.e., budding. Iqg1p was identified as an effector for the Cdc42p GTPase, and an IQG1-null strain displayed phenotypes consistent with a role in polarity, cytokinesis, and protein traffic[25,28,63]. In different strain backgrounds, other groups showed Iqg1p to be essential for cytokinesis via a role in actomyosin ring contraction[64,65], to cooperate with the mitotic exit network[66], and to be regulated by the anaphase-promoting complex[67]. Because the actomyosin ring is dispensable for yeast cell growth and cytokinesis, its role in this process has been challenged[68,69]; thus, Iqg1p must play additional or different roles in the cell.

Indeed, Iqg1p was found to bind the axial marker, Bud4p, and the exocyst landmark, Sec3p, and specifies the bud site as well as promotes cytokinesis in a manner that appears to be directly related to a 
role in exocytosis and septum deposition[28]. Iqg1 also binds F-actin and its deletion led to disorganization of actin filaments[25], suggesting a role in bundling F-actin similar to its mammalian counterpart. Furthermore, a null strain of Iqg1p exhibited an enlarged vacuole at restrictive temperatures[25], suggesting additional roles in vacuolar-endosomal trafficking. Support for this can be gleaned from the interaction of mammalian IQGAP1 with the conserved endosomal sorting proteins TSG101 and Alix, members of the ESCORT protein complex[70], suggesting a potentially conserved role in endocytosis. Interaction of IQGAP1 with ESCORT proteins may play a role in endosomal sorting as well as in cell abscission, which also requires regulated membrane traffic $[28,63,71,72,73,74]$. Support for this was provided by the phenotype of iqglsec3 double mutant, which exhibited defects in bud site selection and septum deposition[28]. Further work is required for elucidating how and which trafficking pathway does Iqg1p regulate. Nevertheless IQGAP1's role in trafficking appears to be conserved in higher organisms, which I discuss below.

\section{Mammalian IQGAP1 and Protein Traffic}

A similar role for mammalian IQGAP1 in protein traffic has recently become evident and could be gleaned from earlier observations. Several studies showed that IQGAP1 regulates cell-cell junctions in epithelial cells[75,76,77,78], which are considered to be sites for polarized exocytosis[1,2,79,80,81]. It was also shown to influence membrane trafficking in gastric parietal cells[82,83]. Moreover, a negative role for IQGAP1 in secretion has also been reported. Delivery of secretory lysosomes in the immune system requires the clearing of both actin and IQGAP1 from the target site of the plasma membrane[84], and depletion of IQGAP1 by RNAi in mast cells mildly enhanced agonist-stimulated histamine secretion[85]. The mechanism underlying IQGAP1's role in these cellular processes has begun to emerge.

Recent evidence suggests that IQGAP1 is a regulator of membrane traffic. IQGAP1 both positively and negatively regulates exocytosis by regulating CDC42 GTPase. The N-terminal domain of IQGAP1 binds Exo70 of the exocyst[29], the conserved protein complex that mediates the tethering of secretory vesicles to sites of active exocytosis[56,86,87]. Binding of IQGAP1 to CDC42 or constitutive phosphorylation of the C-terminal Ser1443 appears to dissociate the exocyst from the N-terminal domain, attenuates secretion[29], enhances cell migration, and increases cell proliferation[44]. Expression of the $\mathrm{N}$-terminal domain generated a dominant-positive effect on secretion and cell size, whereas expression of the C-terminal domain acted as inhibitor of secretion and promoter of migration and cell proliferation[29,44]. Binding of the exocyst to the IQGAP1 C-terminus has also been reported to enhance cell invasion downstream of RhoA and CDC42[88]. Together, these data support the idea that IQGAP1 regulates secretion by different domains to regulate cellular responses to different signaling cues. A plausible mechanism by which IQGAP1 can achieve these differential roles is by serving as an unconventional GEF/GAP/effector by acting as a conformational switch, itself regulated by phosphorylation and protein-protein interactions (Fig. 1B)[27,29,44]. In this capacity, IQGAP1 may serve as a signaling hub that acts as both an upstream regulator and a downstream effector of converging signaling pathways, which may explain its ubiquitous localization in the cell.

\section{PERSPECTIVE: HOW IQGAP1 MIGHT REGULATE PROTEIN TRAFFIC}

Accumulating evidence predicts that IQGAP1 can potentially regulate protein trafficking at two levels: the level of protein synthesis/translation and the level of docking/tethering by regulating the assemblydisassembly of actin filaments at the exocytic targets. The former may be mediated via binding to mTOR, as discussed below, whereas the latter may occur through binding to the exocyst, which has also been implicated in actin dynamics through the Arp2/3 complex[18]. These roles are likely regulated by CDC42 and $\mathrm{PKC} \varepsilon$ as discussed earlier. 
IQGAP1 plays an important role in regulating protein synthesis and translocation[29], perhaps through binding to mTOR[44] and/or translocon subunit Sec61 $\beta$ [29]. Similarly, both yeast and mammalian exocyst have been implicated in translational control through binding to their respective Sec61 $\beta$ translocon subunit $[60,89,90]$. Significantly, the Sec61 $\beta$ subunit has recently been implicated in membrane traffic to the plasma membrane and the nucleus[91,92], which may indicate a direct connection between protein translation, translocation, and vesicular traffic.

The evolutionarily conserved serine/threonine kinase target of rapamycin (TOR) is known as the center for cell growth control and has been implicated in various aspects of protein traffic. Yeast and mammalian TORs are composed of two distinct complexes, TORC1 and TORC2 (reviewed in Fingar and Blenis[93], Sabatini[94], Wullschleger et al.[95], and Hall[96]). The mTORC1 is a rapamycin-sensitive complex that regulates accumulation of cell mass by activating mRNA translation and ribosome biogenesis by directly phosphorylating, thereby activating its effector S6K1 (ribosomal S6 kinase 1), a regulator of cell size. The mTORC2 is rapamycin insensitive, but it responds to long-term rapamycin treatment and is considered to act upstream of mTORC1 by directly activating Akt, an effector of PI3K[97]. Akt1, in turn, activates mTORC1 by inhibiting the GAP TSC1/2 complex, thus activating the GTPase Rheb, which activates mTOR. This activation process by the PI3K-Akt is regulated by a negative feedback loop, whereby activated S6K1 inhibits Akt activity by phosphorylating the insulin receptor substrate 1 (IRS-1), thus blocking insulin signaling to Akt[98]. This indicates that mTORC1 and mTORC2 regulate one another during the cell cycle; however, their upstream regulators are not well defined[99].

Recently, mTORC1 has also been shown to affect actin remodeling and protein traffic. Disruption of the mTOR-raptor complex by rapamycin or raptor-siRNA prevented F-actin remodeling and impaired cell motility, through the eukaryotic initiation factor 4E (eIF4E)-binding protein 1 (4E-BP1-5A) subunit, a repressor of protein synthesis[100]. It is unclear whether protein transport to the leading edge of these cells was affected and the role for mTOR pathway in post-Golgi vesicular traffic is only beginning to emerge. It has been suggested that mTOR and Akt1 regulate cell size by influencing the trafficking of surface transporters for nutrients, such as the glucose transporter[101]. Further, hyperactivation of mTOR by down-regulation of TSC1/2 was suggested to disrupt protein trafficking. This was attributed to disruption of microtubule organization as a result of mTOR binding and phosphorylation of CLIP170[102], the microtubule-binding protein that also binds IQGAP1[39]. More recently, mTOR and Akt1 were implicated in TGN to endosome retrograde pathway through an interaction with the Golgiresident protein GOLPH3[11]. These findings, together with the finding that IQGAP1 interacts with the mTOR pathway[44], provide a platform for elucidating a role for an mTOR-IQGAP1 signaling pathway in regulating post-Golgi traffic and tethering. They further suggest that translation, translocation, and vesicular traffic are likely ordered via a regulatory feedback signaling mechanism in which interplay of IQGAP1-CDC42-PKC $\varepsilon$ plays an important regulatory role upstream of the mTOR pathway. Exciting times are ahead for elucidating this signaling pathway.

\section{ACKNOWLEDGMENT}

Work in the Osman laboratory was supported by grants from the NIH-NCI (CA104285) and The American Society for Cell Biology (ASCB).

\section{REFERENCES}

1. Mostov, K.E., Verges, M., and Altschuler, Y. (2000) Membrane traffic in polarized epithelial cells. Curr. Opin. Cell Biol. 12, 483-490.

2. Fölsch, H., Mattila, P.E., and Weisz, O.A. (2009) Taking the scenic route: biosynthetic traffic to the plasma membrane in polarized epithelial cells. Traffic 10, 972-981. 
3. Ridley, A.J. (2006) Rho GTPases and actin dynamics in membrane protrusions and vesicle trafficking. Trends Cell Biol. 16, 522-529.

4. Loubéry, S., Wilhelm, C., Hurbain, I., Neveu, S., Louvard, D., and Coudrier, E. (2008) Different microtubule motors move early and late endocytic compartments. Traffic 9, 492-509.

5. Stehbens, S.J., Akhmanova, A., and Yap, A.S. (2009) Microtubules and cadherins: a neglected partnership. Front. Biosci. 14, 3159-3167.

6. Lopez, J.A., Burchfield, J.G., Blair, D.H., Mele, K., Ng, Y., Vallotton, P., James, D.E., and Hughes, W.E. (2009) Identification of a distal GLUT4 trafficking event controlled by actin polymerization. Mol. Biol. Cell 20, 3918-3929.

7. Aridor, M. and Hannan, L.A. (2000) Traffic jam: a compendium of human diseases that affect intracellular transport processes. Traffic 1, 836-851.

8. Merte, J., Jensen, D., Wright, K., Sarsfield, S., Wang, Y., Schekman, R., and Ginty, D.D. (2010) Sec24b selectively sorts Vangl2 to regulate planar cell polarity during neural tube closure. Nat. Cell Biol. 12, 41-46.

9. Seabra, M.C., Mules, E.H. and Hume, A.N. (2002) Rab GTPases, intracellular traffic and disease. Trends Mol. Med. $\mathbf{8}, 23-30$.

10. Giussani, P., Brioschi, L., Bassi, R., Riboni, L., and Viani, P. (2009) Phosphatidylinositol 3-kinase/AKT pathway regulates the endoplasmic reticulum to Golgi traffic of ceramide in glioma cells J. Biol. Chem. 284, 5088-5096.

11. Scott, K.L. et al. (2009). GOLPH3 modulates mTOR signaling and rapamycin sensitivity in cancer. Nature 459, $1085-1090$.

12. Whyte, J.R. and Munro, S. (2001) The Sec34/35 Golgi transport complex is related to the exocyst, defining a family of complexes involved in multiple steps of membrane traffic. Dev. Cell 1, 527-537.

13. Whyte, J.R.C. and Munro, S. (2002) Vesicle tethering complexes in membrane traffic. J. Cell Sci.115, $2627-2637$.

14. Grosshans, B.L., Ortiz, D., and Novick, P. (2006) Rabs and their effectors: achieving specificity in membrane traffic. Proc. Natl. Acad. Sci. U. S. A. 103, 11821-11827.

15. Luna, A., Matas, O.B., Martínez-Menárguez, J.A., Mato, E., Durán, J.M., Ballesta, J., Way, M., and Egea. G. (2002) Regulation of protein transport from the Golgi complex to the endoplasmic reticulum by CDC42 and N-WASP. Mol. Biol. Cell 13, 866-879.

16. Salvarezza, S.B., Deborde, S., Schreiner, R., Campagne, F., Kessels, M.M., Qualmann, B., Caceres, A., Kreitzer, G., and Rodriguez-Boulan, E. (2009) LIM kinase 1 and cofilin regulate actin filament population required for dynamindependent apical carrier fission from the trans-Golgi network. Mol. Biol. Cell 20, 438-451.

17. Egorov, M.V., Capestrano, M., Vorontsova, O.A., Di Pentima, A., Egorova, A.V., Mariggio, S., Ayala, M.I., Tete, S., Gorski, J.L., Luini, A., et al. (2009) Faciogenital dysplasia protein (FGD1) regulates export of cargo proteins from the Golgi complex via Cdc42 activation. Mol. Biol. Cell 20, 2413-2427.

18. Zuo, X., Zhang, J., Zhang, Y., Hsu, S.C., Zhou, D., and Guo, W. (2006) Exo70 interacts with the Arp2/3 complex and regulates cell migration. Nat. Cell Biol. 8, 1383-1388.

19. Vitale, M.L., Delcastillo, A.R., Tchakarov, L., and Trifaro, J.M. (1991) Cortical filamentous actin disassembly and scinderin redistribution during chromaffin cell stimulation precede exocytosis, a phenomenon not exhibited by gelsolin. J. Cell Biol. 113, 1057-1067.

20. Xue, R., Zhao, Y., Su, L., Ye, F., and Chen, P. (2009) PKC epsilon facilitates recovery of exocytosis after an exhausting stimulation. Pflugers Arch. 458(6), 1137-1149.

21. Vardjan, N., Stenovec, M., Jorgacevski, J., Kreft, M., Grilc, S., and Zorec, R. (2009) The fusion pore and vesicle cargo discharge modulation. Ann. N. Y. Acad. Sci. 1152, 135-144.

22. Bhat, P. and Thorn, P. (2009) Myosin 2 maintains an open exocytic fusion pore in secretory epithelial cells. Mol. Biol. Cell. 20, 1795-1803.

23. Park, Y.S., Hur, E.M., Choi, B.H., Kwak, E., Jun, D.J., Park, S.J., and Kim, K.T. (2006) Involvement of protein kinase C-epsilon in activity-dependent potentiation of large dense-core vesicle exocytosis in chromaffin cells. $J$. Neurosci. 26, 8999-9005.

24. Mendez, C.F., Leibiger, I.B., Leibiger, B., Høy, M., Gromada, J., Berggren, P.O., and Bertorello, A.M. (2003) Rapid association of protein kinase C-epsilon with insulin granules is essential for insulin exocytosis. J. Biol. Chem. 278, 44753-44757.

25. Osman, M.A. and Cerione, R.A. (1998) Iqg1p, a yeast homologue of the mammalian IQGAPs, mediates cdc42p effects on the actin cytoskeleton. J. Cell Biol. 142, 443-455.

26. Bensenor, L., Kan, H.-M., Wang, N., Wallrabe, H., Davidson, L.A., Cai, Y., Schafer, D.A., and Bloom, G.S. (2007) IQGAP1 regulates cell motility by linking growth factor signaling to actin assembly. J. Cell Sci. 120, 658-669.

27. Le Clainche, C., Schlaepfer, D., Ferrari, A., Klingauf, M., Grohmanova, K., Veligodskiy, A., Dirdy, D., Le, D., Egile, C., Carlier, M.-F., and Kroschewski, R. (2007) IQGAP1 stimulates actin assembly through the N-WaspArp2/3 pathway. J. Biol. Chem. 282, 426-435.

28. Osman, M.A., Konopka, J.B., and Cerione, R.A. (2002) Iqg1p links spatial and secretion landmarks to polarity and cytokinesis. J. Cell Biol. 159, 601-611.

29. Rittmeyer, E.N., Daniel, S., Hsu, S.-C., and Osman, M.A. (2008) A dual role for IQGAP1 in regulating exocytosis. J. Cell Sci. 121, 391-408. 
30. Grohmanova, K., Schlaepfer, D., Hess, D., Gutierrez, P., Beck, M., and Kroschewski, R. (2004) Phosphorylation of IQGAP1 modulates its binding to Cdc42, revealing a new type of Rho-GTPase regulator. J. Biol. Chem. 279, 48495-48504.

31. Brill, S., Li, S., Lyman, C.W., Church, D.M., Wasmuth, J.J., Weissbach, L., Bernards, A., and Snijders, A.J. (1996) The Ras GTPase-activating-protein-related human protein IQGAP2 harbors a potential actin binding domain and interacts with calmodulin and Rho family GTPases. Mol. Cell. Biol. 16, 4869-4878.

32. Kuroda, S., Fukata, M., Kobayashi, K., Nakafuku, M., Nomura, N., Iwamatsu, A., and Kaibuchi, K. (1996) Identification of IQGAP as a putative target for the small GTPases, CDC42 and Rac1. J. Biol. Chem. 271, 2336323367.

33. McCallum, S.J., Wu, W.J., and Cerione, R.A. (1996) Identification of a putative effector for Cdc42Hs with high sequence similarity to the RasGAP-related protein IQGAP1 and a Cdc42Hs binding partner IQGAP2. J. Biol. Chem. 271, 21732-21737.

34. Bashour, A.-M., Fullerton, A.T., Hart, M.J., and Bloom, G.S. (1997) IQGAP1, a Rac- and Cdc42-binding protein, is an actin-binding protein that cross-links microfilaments. J. Cell Biol. 137, 1555-1566.

35. Kurella, V.B, Richard, J.M., Parke, C.L., Lecour, L.F., Jr., Bellamy, H.D., and Worthylake, D.K. (2009) Crystal structure of the GTPase-activating protein-related domain from IQGAP1. J. Biol. Chem. 284, 14857-14865.

36. Brown, D. and Sacks, D.B. (2006) IQGAP1 in cellular signaling: bridging the GAP. Trends Cell Biol. 16, $242-249$.

37. Mateer, S.C., Wang, N., and Bloom, G.S. (2003) IQGAPs: integrators of the cytoskeleton, cell adhesion machinery, and signaling networks. Cell Motil. Cytoskeleton 55, 147-155.

38. Roy, M., Li, Z., and Sacks, D.B. (2005) IQGAP1 is a scaffold for mitogen-activated protein kinase signaling. Mol. Cell. Biol. 25, 7940-7952.

39. Fukata, M., Watanabe, T., Noritake, J., Nakagawa, M., Yamaga, M., Kuroda, S., Matsuura, Y., Iwamatsu, A., Perez, F., and Kaibuchi, K. (2002) Rac1 and Cdc42 capture microtubules through IQGAP1 and CLIP-170. Cell 109, 873885.

40. Watanabe, T., Wang, S., Noritake, J., Sato, K., Fukata, M., Takefuji, M., Nakagawa, M., Izumi, N., Akiyama, T., and Kaibuci, K. (2004) Interaction with IQGAP1 links APC to Rac1, Cdc42, and actin filaments during cell polarization and migration. Dev. Cell 7, 871-883.

41. Brandt, D.T. and Grosse, R. (2007) Get to grips: steering local actin dynamics with IQGAPs. EMBO reports 8(11), 1019-1023.

42. Mateer, S.T., Morris, L.E., Cromer, D.A., Benseñor, L.B., and Bloom, G.S. (2004) Actin filament binding by a monomeric IQGAP1 fragment with a single calponin homology domain. Cell Motil. Cytoskeleton 58, 231-241.

43. Brandt, D.T., Marion, S., Griffiths, G., Watanabe, T., Kaibuchi, K., and Grosse, R. (2007) Dia1 and IQGAP1 interact in cell migration and phagocytic cup formation. J. Cell Biol. 178, 193-200.

44. Wang, J.-B., Sonn, R., Tekletsadik, Y.K., Samorodnitsky, D., and Osman, M.A. (2009) IQGAP1 regulates cell proliferation through a novel CDC42-mTOR/PI3K pathway. J. Cell Sci. 122, 2024-2033.

45. Chant, J. (1996) Septin scaffolds and cleavage planes in Saccharomyces. Cell 84, 187-190.

46. Longtine M.S. and Bi, E. (2003) Regulation of septin organization and function in yeast. Trends Cell Biol. 8, 403409.

47. Madden, K. and Snyder, M. (1998) Cell polarity and morphogenesis in budding yeast. Annu. Rev. Microbiol. 52, 687-744.

48. Casamayor, A. and Snyder, M. (2002) Bud-site selection and cell polarity in budding yeast. Curr. Opin. Microbiol. 5, 179-176.

49. Johnson, D.I. and Pringle, J.R. (1990) Molecular characterization of CDC42, a Saccharomyces cerevisiae gene involved in the development of cell polarity. J. Cell Biol. 111, 143-152.

50. Pruyne, D., Gao, L., Bi, E., and Bretscher, A. (2004) Stable and dynamic axes of polarity use distinct formin isoforms in budding yeast. Mol. Biol. Cell 11, 4971-4989.

51. Wu, H., Rossi, G., and Brennwald, P. (2008) The ghost in the machine: small GTPases as spatial regulators of exocytosis. Trends Cell Biol. 18, 397-404.

52. Lew, D.J. and Reed, S.I. (1995) Cell cycle control of morphogenesis in budding yeast. Curr. Opin. Genet. Dev. 5, 17-23.

53. Finger, F. and Novick, P. (1998) Spatial regulation of exocyst: Lessons from yeast. J. Cell Biol. 142, 609-612.

54. Guo, W., Tamanoi, F., and Novick, P. (2001) Spatial regulation of the exocyst complex by Rho1 GTPase. Nat. Cell Biol. 3, 353-360.

55. Nelson, W.J. and Yeaman, C. (2001) Protein trafficking in the exocytic pathway of polarized epithelial cells. Trends Cell Biol. 12, 483-486.

56. Hsu, S.C., TerBush, D., Abraham, M., and Guo, W. (2004) The exocyst complex in polarized exocytosis. Int. Rev. Cytol. 233, 243-265.

57. Munson, M. and Novick, P. (2006) The exocyst defrocked, a framework of rods revealed. Nat. Struct. Mol. Biol. 13, 577-581.

58. Bowser, R., Müller, H., Govindan, B., and Novick, P. (1992) Sec8p and Sec15p are components of a plasma membrane-associated $19.5 \mathrm{~S}$ particle that may function downstream of Sec4p to control exocytosis. J. Cell Biol. 118, 1041-1056. 
59. TerBush, D.R. and Novick, P. (1995) Sec6, Sec8, and Sec15 are components of a multisubunit complex which localizes to small bud tips in Saccharomyces cerevisiae. J. Cell Biol. 130, 299-312.

60. Wiederkehr, A., Du, Y., Pypaert, M., Ferro-Novick, S., and Novick, P. (2003) Sec3p is needed for the spatial regulation of secretion and for the inheritance of the cortical endoplasmic reticulum. Mol. Biol. Cell 14, 4770-4782.

61. Zhang, X., Bi, E., Novick, P., Du, L., Kozminski, K.G., Lipschutz, J.H., and Guo, W. (2001) Cdc42 interacts with the exocyst and regulates polarized secretion. J. Biol. Chem. 276, 46745-46750.

62. Wu, H., Turner, C., Gardner, J., Temple, B., and Brennwald, P. (2010) The Exo70 subunit of the exocyst is an effector for both Cdc42 and Rho3 function in polarized exocytosis. Mol. Biol. Cell 21, 430-442.

63. Osman, M.A. and Cerione, R.A. (2006) Actin doesn't do the locomotion. Secretion drives cell polarization. In Protein Trafficking: Mechanisms and Regulation. Segev, N., Ed. Landes Bioscience, Georgetown, TX and Eurekah.com.

64. Epp, J.A. and Chant, J. (1997) An IQGAP-related protein controls actin-ring formation and cytokinesis in yeast. Curr. Biol. 7, 921-929.

65. Lippincott, J. and Li, R. (1998) Sequential assembly of myosin II, an IQGAP-like protein, and filamentous actin to a ring structure involved in budding yeast cytokinesis. J. Cell Biol. 140, 355-366.

66. Corbett, M, Xiong, Y., Boyne, J.R., Wright, D.J., Munro, E., and Price, C. (2006) IQGAP and mitotic exit network (MEN) proteins are required for cytokinesis and re-polarization of the actin cytoskeleton in the budding yeast, Saccharomyces cerevisiae. Eur. J. Cell Biol. 85, 1201-1215.

67. Ko, N., Nishihama, R., Tully, G.H., Ostapenko, D., Solomon, M.J., Morgan, D.O., and Pringle, J.R. (2007) Identification of yeast IQGAP (Iqg1p) as an anaphase-promoting-complex substrate and its role in actomyosin-ringindependent cytokinesis. Mol. Biol. Cell 18, 5139-5153.

68. Bi, E., Maddox, P., Lew, D.J., Salmon, E.D., McMillan, J.N., Yeh, E., and Pringle, J.R. (1998) Involvement of an actomyosin contractile ring in Saccharomyces cerevisiae cytokinesis. J. Cell Biol. 142, 1301-1312.

69. Bi, E. (2001) Cytokinesis in budding yeast: the relationship between actomyosin ring function and septum formation. Cell Struct. Funct. 26, 529-537.

70. Morita, E., Sandrin, V., Chung, H.-Y., Morham, S.G., Gygi, S.P., Rodesch, C.K., and Sundquis, W.I. (2007) Human ESCRT and ALIX proteins interact with proteins of the midbody and function in cytokinesis. EMBO J. 26, 42154227.

71. Gromley, A., Yeaman, C., Rosa, J., Redick, S., Chen, C.-T. Mirabelle, S., Guha, M., Sillibourne, J., and Doxsey, S.J. (2005) Centriolin anchoring of exocyst and SNARE complexes at midbody is required for secretory vesiclemediated abscission. Cell 123, 75-87.

72. VerPlank, L. and Li, R. (2005) Cell cycle-regulated trafficking of Chs2 controls actomyosin ring stability during cytokinesis. Mol. Biol. Cell 16, 2529-2543.

73. Dhonukshe, P., Baluska, F., Schlicht, M., Hlavacka, A., Samaj, J., Friml, J., and Gadella, T.W., Jr. (2006) Endocytosis of cell surface material mediates cell plate formation during plant cytokinesis, Dev. Cell 10, 137-150.

74. Reichardt, I., Stierhof, Y.-D., Mayer, U., Richter, S., Schwarz, H., Schumacher, K., and Jürgens, G. (2007) Plant cytokinesis requires de novo secretory trafficking but not endocytosis. Curr. Biol. 17, 2047-2053.

75. Fukata, M., Kuroda, S., Nakagawa, M., Kawajiri, A., Itoh, N., Shoji, I., Matsuura, Y., Yonehara, S., Kikuchi, A., and Kaibuchi, K. (1999) Cdc42 and Racl regulate the interaction of IQGAP1 with $\beta$-catenin. J. Biol. Chem. 274, 26044-26050.

76. Fukata, M., Nakagawa, M., Itoh, N., Kawajiri, A., Yamaga, M., Kuroda, S., and Kaibuchi, K. (2001) Involvement of IQGAP1, an effector of Rac1 and Cdc42 GTPase, in cell-cell dissociation during cell scattering. Mol. Cell. Biol. 21, 2165-2183.

77. Noritake, J., Fukata, M., Sato, K., Nakagawa, M., Watanabe, T., Izumi, N., Wang, S., Fukata, Y., and Kaibuchi, K. (2004) Positive role of IQGAP1, an effector of Rac1, in actin-meshwork formation at sites of cell-cell contact. Mol. Biol. Cell 15, 1065-1076.

78. Noritake, J., Watanabe, T., Sato, K., Wang, S., and Kaibuchi, K. (2005) IQGAP1: a key regulator of adhesion and migration. J. Cell Sci. 118, 2085-2092.

79. Grindstaff, K.K., Yeaman, C., Anandasabapathy, N., Hsu, S.C., Rodriguez-Boulan, E., Scheller, R.H., and Nelson, W.J. (1998) Sec6/8 complex is recruited to cell-cell contacts and specifies transport vesicle delivery to the basallateral membrane in epithelial cells. Cell 93, 731-740.

80. Kreitzer, G., Schmoranzer, J., Low, S.H., Li, X., Gan, Y., Weimbs, T., Simon, S.M., and Rodriguez-Boulan, E. (2003) Three-dimensional analysis of post-Golgi carrier exocytosis in epithelial cells. Nat. Cell Biol. 5, 126-136.

81. Cao, Z. et al. (2008) Use of fluorescence-activated vesicle sorting for isolation of Naked2-associated, basolaterally targeted exocytic vesicles for proteomics analysis. Mol. Cell. Proteomics 7, 1651-1667.

82. Zhou, R., Guo, Z., Watson, C., Chen, E., Kong, R., Wang, W., and Yao, X. (2003) Polarized distribution of IQGAP proteins in gastric parietal cells and their roles in regulated epithelial cell secretion. Mol. Biol. Cell 14, 1097-1108.

83. Chew, C.S., Okamoto, C.T., Chen, X., and Qin, H.Y. (2005) IQGAPs are differentially expressed and regulated in polarized gastric epithelial cells. Am. J. Physiol. 288, G376-G387.

84. Stinchcombe, J.C., Majorovits, E., Bossi, G., Fuller, S., and Griffiths, G.M. (2006) Centrosome polarization delivers secretory granules to the immunological synapse. Nature 443, 462-465. 
85. Psatha, M.I., Razi, M., Koffer, A., Moss, S.E., Sacks, D.B., and Bolsover, S.R. (2007) Targeting of calcium:calmodulin signals to the cytoskeleton by IQGAP1. Cell Calc. 41, 593-605.

86. Hsu, S.C., Ting, A.E., Hazuka, C.D., Davanger, S., Kenny, J.W., Kee, Y., and Scheller, R.H. (1996) The mammalian brain rsec6/8 complex. Neuron 17, 1209-1219.

87. Lipschutz, J.H. and Mostov, K.E. (2002) Exocytosis: the many masters of the exocyst. Curr. Biol. 12, R212-R214.

88. Sakurai-Yageta, M., Recchi, C., Le Dez, G., Sibarita, J.-B., Daviet, L., Camonis, C., D'Souza-Schorey, C., and Chavrier, P. (2008) The interaction of IQGAP1 with the exocyst complex is required for tumor cell invasion downstream of Cdc42 and RhoA. J. Cell Biol. 181, 986-998.

89. Lipschutz, J.H., Lingappa, V.R., and Mostov, K.E. (2003) The exocyst affects protein synthesis by acting on the translocation machinery of the endoplasmic reticulum. J. Biol. Chem. 278, 20954-20960.

90. Toikkanen, J.H., Miller, K.J., Soderlund, H., Jantti, J., and Keranen, S. (2003) The $\beta$ subunit of the Sec61p endoplasmic reticulum translocon interacts with the exocyst complex in Saccharomyces cerevisiae. J. Biol. Chem. 278, 20946-20953.

91. Kelkar, A. and Dobberstein, B. (2009) Sec61ß, a subunit of the Sec61 protein translocation channel at the endoplasmic reticulum, is involved in the transport of Gurken to the plasma membrane. BMC Cell Biol. 10,11.

92. Liao, H.-J. and Carpenter, G. (2007) Role of the Sec61 translocon in EGF receptor trafficking to the nucleus and gene expression. Mol. Biol. Cell 18, 1064-1072.

93. Fingar, D.C. and Blenis, J. (2004) Target of rapamycin (TOR): an integrator of nutrient and growth factor signals and coordinator of cell growth and cell cycle progression. Oncogene 23, 3151-3171.

94. Sabatini, D. (2006) mTOR and cancer: insights into a complex relationship. Nature 6, 729-734.

95. Wullschleger, S., Loewith, R., and Hall, M.N. (2006) TOR signaling in growth and metabolism. Cell 124, 471-484.

96. Hall, M.N. (2008) mTOR-what does it do? Transplant. Proc. 40, S5-8.

97. Sarbassov, D.D., Siraj, M.A., Segupta, S., Sheen, J.-H., Hsu, P.P., Bagley, A.F., Markhard, A.L., and Sabatini, D.M. (2006) Prolonged rapamycin treatment inhibits TORC2 assembly and Akt/PKB. Mol. Cell 22, 159-168.

98. Harrington, L.S., Findlay, G.M., and Lamb, R.F. (2005) Restraining PI3K: mTOR signaling goes back to the membrane. Trends Biochem. Sci. 30, 35-42.

99. Sturgill, T.W. and Hall, M.N. (2007) Holding back TOR advances mitosis. Nat. Cell Biol. 9, 1221-1222.

100. Liu, L., Chen, L., Chung, J., and Huang, S. (2008) Rapamycin inhibits F-actin reorganization and phosphorylation of focal adhesion proteins. Oncogene 27, 4998-5010.

101. Edinger, A.L. and Thompson, C.B. (2002) Akt maintains cell size and survival by increasing mTOR-dependent nutrient uptake. Mol. Biol. Cell 13, 2276-2288.

102. Jiang, X. and Yeung, R.S. (2006) Regulation of microtubule-dependent protein transport by the TSC $2 / \mathrm{mammalian}$ target of rapamycin pathway. Cancer Res. 66, 5258-5269.

This article should be cited as follows:

Osman, M.A. (2010) An emerging role for IQGAP1 in regulating protein traffic. TheScientificWorldJOURNAL 10, 944-953. DOI 10.1100/tsw.2010.85. 

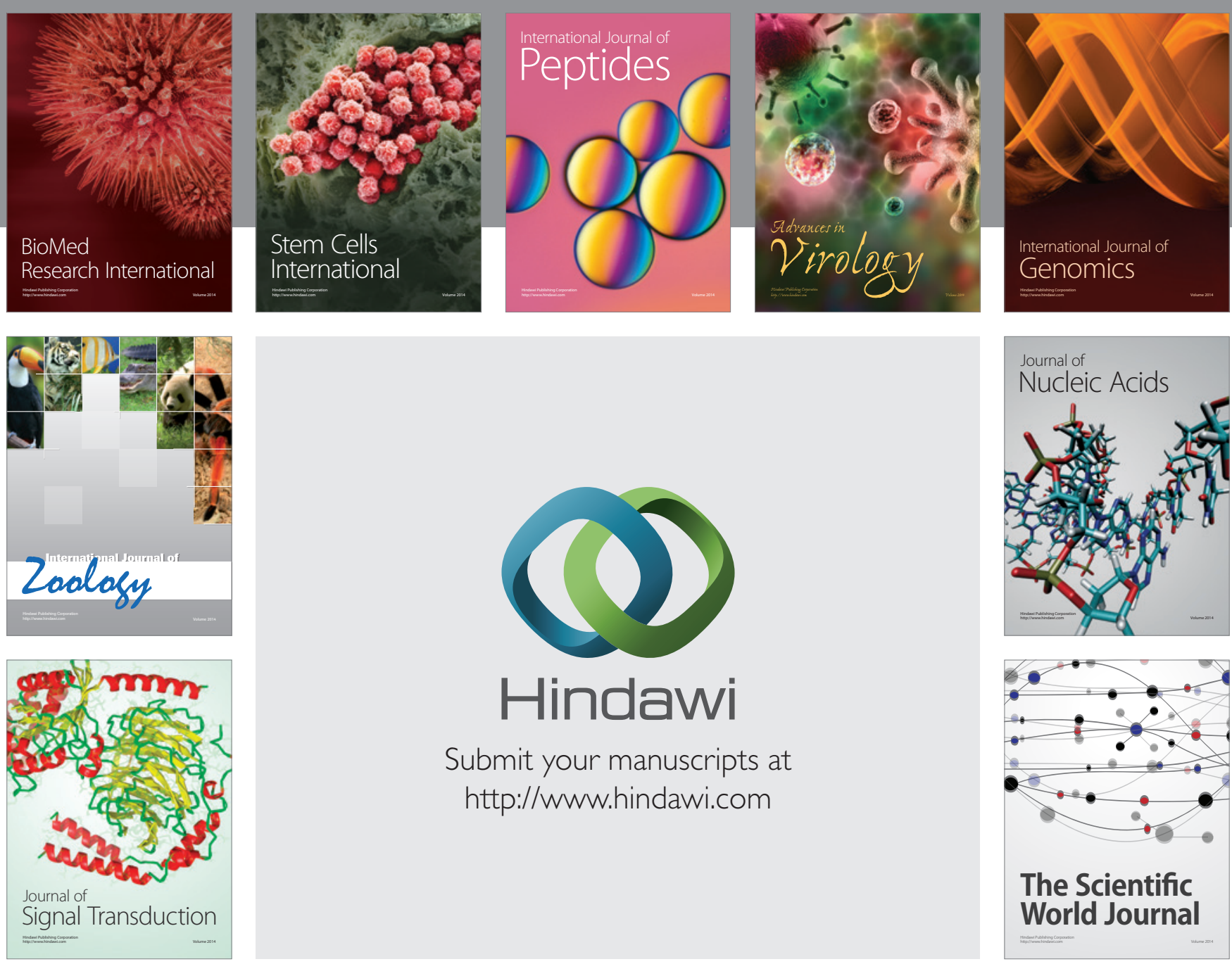

Submit your manuscripts at

http://www.hindawi.com
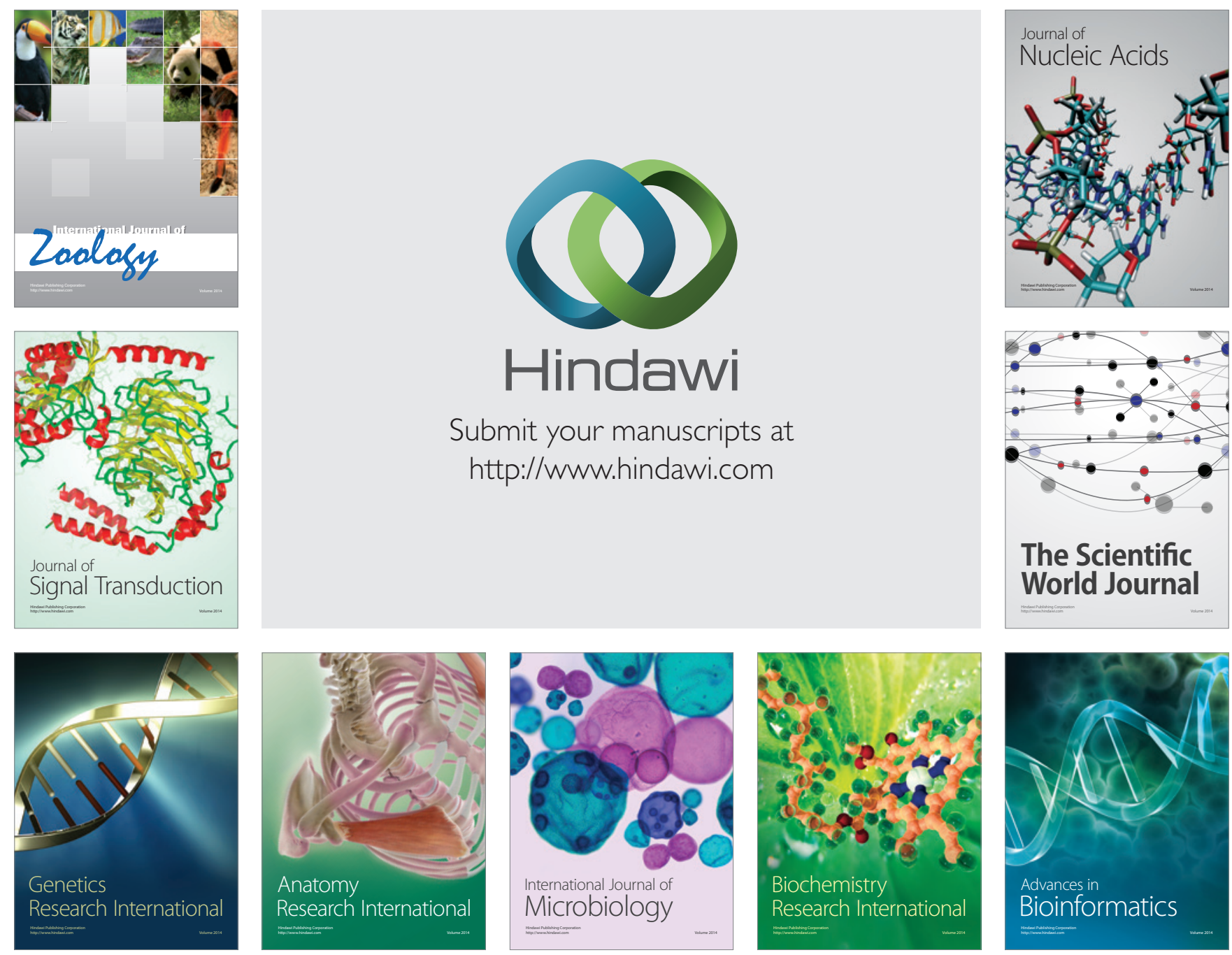

The Scientific World Journal
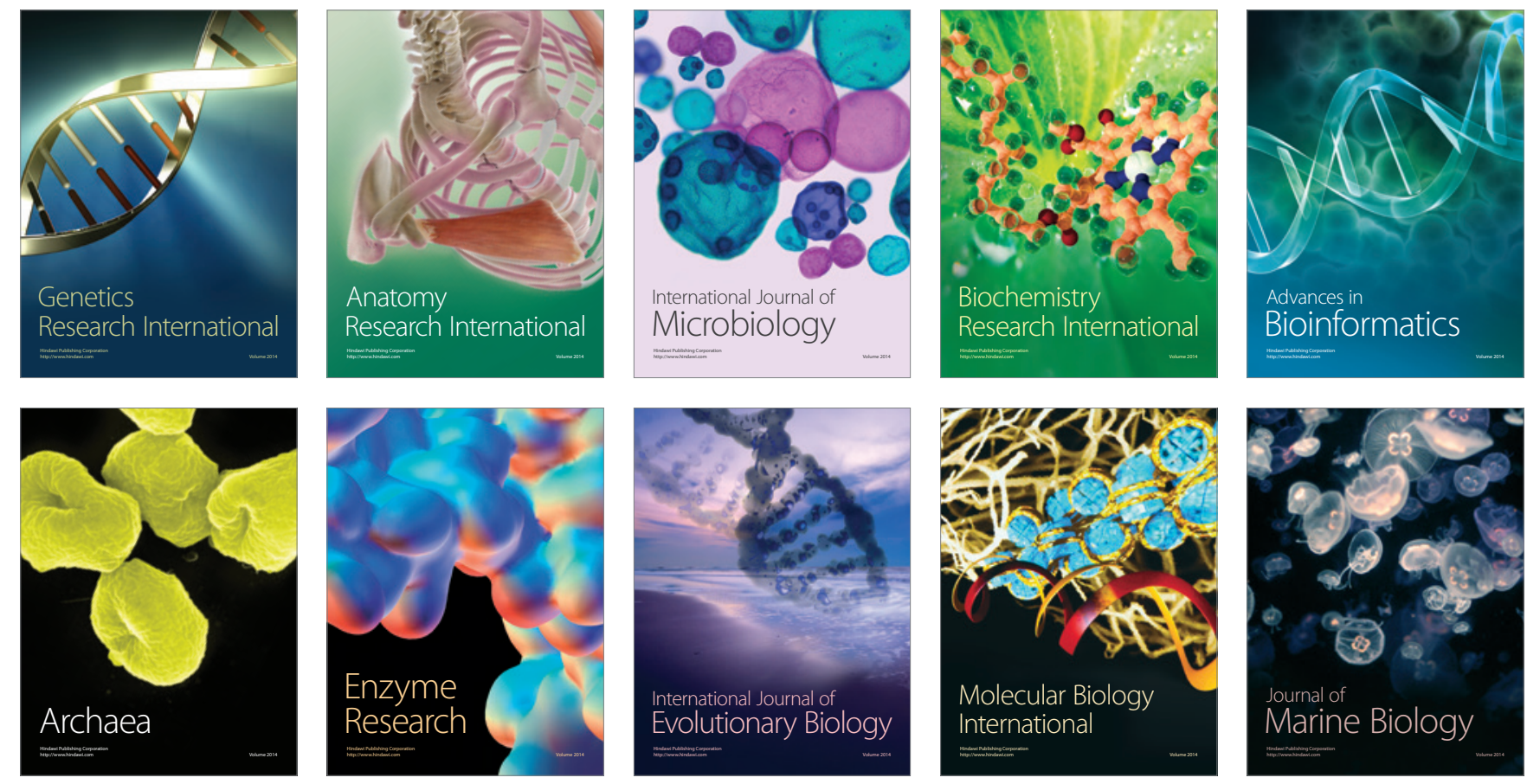